5-30-2013

\title{
Polymerized Hemin as An Electrocatalytic Platform for Peroxynitrite's Oxidation and Detection
}

Serban F. Peteu

Cleveland State University

Tiyash Bose

Cleveland State University

Mekki Bayachou

Cleveland State University, M.BAYACHOU@csuohio.edu

Follow this and additional works at: https://engagedscholarship.csuohio.edu/scichem_facpub

Part of the Chemistry Commons

How does access to this work benefit you? Let us know!

\section{Recommended Citation}

Peteu, Serban F.; Bose, Tiyash; and Bayachou, Mekki, "Polymerized Hemin as An Electrocatalytic Platform for Peroxynitrite's Oxidation and Detection" (2013). Chemistry Faculty Publications. 323.

https://engagedscholarship.csuohio.edu/scichem_facpub/323 
Polymerized hemin as an electrocatalytic platform for peroxynitrite's oxidation and detection

Serban F. Peteu , Tiyash Bose , Mekki Bayachou 


\section{Introduction}

Peroxynitrite [1] $\left(\mathrm{ONOO}^{-}\right)$is a major cytotoxic agent, implicated in a plethora of pathological conditions. There is a great and increasing interest in evaluating its role and impact as an oxidant in vivo [2-6]. The patho-physiological effects of superoxide [7] and nitric oxide [8] are now well established in literature. However, the effects and roles of their recombination product, peroxynitrite, seem to emerge only recently. The peroxynitrite anion $\left(\mathrm{ONOO}^{-}\right)$ is believed to be a major cytotoxic agent and it is lately under heavy scrutiny [2-6]. Peroxynitrite is formed by the fast reaction of NO with superoxide anion $\left(\mathrm{O}_{2}{ }^{\bullet-}\right)$, and it displays a wide range of biochemical reactivity, including (a) nitrating proteins (tyrosine residues), carbohydrates and nucleic acids, (b) oxidizing lipids, thiol groups, Fe/S and $\mathrm{Zn} / \mathrm{S}$ centers, and (c) transforming oxyhemoglobin to methemoglobin. Although this species is charged, it can freely cross the cytoplasmic membrane of cells when protonated $[9,10]$.

The frequent coexistence of $\mathrm{NO}$ and $\mathrm{O}_{2}{ }^{--}$would imply that peroxynitrite is being formed throughout the human body [11]. Due to its widespread reactivity, $\mathrm{ONO}_{2}{ }^{-}$has been linked to several pathological conditions such as acute ischemia-reperfusion injury, arthritis, carcinogenesis, Alzeimer's and Parkinson's diseases, and AIDS to cite a few. Peroxynitrite decomposition by porphyrin complexes has been investigated as a way to neutralize the inflammatory effects of this reactive metabolite. Recently, several groups investigating water soluble manganese and iron porphyrins have found that these compounds catalytically decompose peroxynitrite [12-15]. Interestingly, elsewhere metallo-porphyrins have been electropolymerized as adherent films on carbon electrodes $[16,17]$ for sensing and for fundamental investigations of catalysis. More recently, the hemin-modified carbon electrodes have been employed for the reduction of organohalides [18], the electrochemical study and quantification of tryptophan and its derivatives [19], or as a sensor for superoxide [20].

Peroxynitrite detection and quantitation are increasingly sought, and often represent the gate to unravel pathophysiological routes involving this metabolite [2-6]. Reported detection methods for peroxynitrite [21] include oxidation of fluorescent probes, EPR spectroscopy, chemiluminescence, immunohistochemistry, and probe nitration; however, these are more difficult to apply for real-time quantification due to their inherent complexity. The electrocatalytic detection of peroxynitrite is a simpler and more convenient technique. A study investigating the electrochemical signature of peroxynitrite has been reported [22]. Another study reported amperometric microsensing of peroxynitrite [23]. Recently, we have reported the use of layered composite films of poly(3,4-ethylenedioxythiophene) (PEDOT) and hemin (iron protoporphyrin IX) as a platform for amperometric measurement of peroxynitrite [24]. The purpose of this work is to investigate the inherent electrocatalytic performance of electropolymerized hemin thin films on glassy carbon electrodes and carbon fiber microelectrodes for the catalytic oxidation of peroxynitrite. Additionally, the hemin-modified electrodes are assessed as possible simple and easy-to-prepare peroxynitrite sensors for analysis in both standing solutions and in flow-through systems.

\section{Experimental}

\section{Peroxynitrite synthesis}

Several synthetic methods have been reported for the preparation of peroxynitrite [25-28]. The method we used was the two-phase displacement reaction with the hydroperoxide anion in the aqueous phase and the isoamyl nitrite in the organic phase [29]. The product, peroxynitrite, remained in the aqueous phase, whereas isoamyl alcohol formed in the organic phase along with the unreacted isoamyl nitrite. The aqueous phase contained some isoamyl alcohol and the unreacted hydrogen peroxide, but no isoamyl nitrite. Removal of isoamyl alcohol, and traces of isoamyl nitrite, was accomplished by washing the aqueous phase with dichloromethane and chloroform. The hydrogen peroxide was removed by passing the solutions through a manganese dioxide column. The peroxynitrite, with a final concentration of $750 \mathrm{mM}$, was stored in $5 \mathrm{~mL}$ aliquots at $-80^{\circ} \mathrm{C}$. Its concentration was assessed by UV-vis at $302 \mathrm{~nm}$, using the extinction coefficient $\varepsilon_{302}=1705 \mathrm{~mol}^{-1} \mathrm{~cm}^{-1}$ [30], both before and after every electroanalytical test. During these experiments, solutions are allowed to thaw and are kept on ice to minimize the spontaneous peroxynitrite decomposition during the experiment.

\section{Chemicals}

The iron protoporphyrin IX (hemin) and protoporphyrin were purchased from Sigma-Aldrich, St. Louis, Mo. Deionized (DI) water was obtained from a Barnstead ultrapure water system Model D8961. Water resistivity was at least $18.2 \mathrm{M} \Omega \mathrm{cm}$. All other chemicals were reagent grade and were used as received.

\section{Preparation of hemin-modified GC electrodes}

Films of electropolymerized porphyrins were deposited on freshly cleaned GC electrodes. Prior to coating, these were polished consecutively on a Buehler polisher using the 400 grit Carbimet disks, then on a microcloth using $0.3 \mu \mathrm{m}$ alumina, and later with $0.05 \mu \mathrm{m}$ alumina slurry. The electrodes were subsequently sonicated for $60 \mathrm{~s}$, then rinsed and dried in a nitrogen stream. The hemin films were electropolymerized from a solution of $1.5 \mathrm{mM}$ hemin monomer, in the presence of $0.1 \mathrm{M}$ tetrabutylammonium tetrafluoroborate $\left(\mathrm{TBABF}_{4}\right)$ in dichloromethane. The glassy carbon electrode was immersed in the hemin solution and cycled at $50 \mathrm{mV} \mathrm{s}^{-1}$ between $0 \mathrm{~V}$ and $+2.0 \mathrm{~V}$ vs. $\mathrm{Ag} / \mathrm{AgCl}$, under a nitrogen gas blanket. After each modification, the electrode was thoroughly rinsed and the electrodeposited film flushed with pure water to remove excess material, and then allowed to dry under a stream of nitrogen $\left(\mathrm{N}_{2}\right)$ gas.

\section{. Apparatus and procedures}

The cyclic voltammetry experiments were performed in a three-electrode configuration cell on a BAS 100B electrochemical workstation. All electrochemical experiments were performed at room temperature $22 \pm 2{ }^{\circ} \mathrm{C}$. The $\mathrm{Ag} / \mathrm{AgCl}$ electrode was used as the reference electrode, and all potentials reported here are $v s$. this reference. A platinum wire was used as the auxiliary. The working electrode was either glassy carbon electrodes (CHI Inc., Austin, TX) or homemade carbon fiber microelectrodes (Goodfellow Corp., Devon, PA). The time-based amperometric calibration tests were performed using the $\mathrm{CHI}$ Instruments Model 440 electrochemical station with the same electrochemical cell, the working electrode being polarized at $+750 \mathrm{mV}$ unless otherwise noted. Just before use, a sealed flask containing the peroxynitrite stock solution was thawed at room temperature and the oxygen was removed by purging with nitrogen gas for at least $30 \mathrm{~min}$. Peroxynitrite aliquots were added with a Hamilton airtight syringe from the sealed flask under the $\mathrm{N}_{2}$ blanket. All dilutions were made fresh just before measurements, in the same de-oxygenated buffer. Graphed data points represent an average of at least three different experiments, unless mentioned otherwise. The glassy carbon electrodes prepared for field emission scanning electron microscopy (FESEM) surface analysis were 12.7-mm-diameter carbon planchets, purchased from Ted Pella Inc. (Redding, CA). Electrical contact was made with a 
copper wire and conductive epoxy on the side of the disc. During electro-polymerization, the glassy carbon disc was electrically insulated with nonconductive epoxy on all exposed surfaces except for the desired active side, i.e. a disc-shaped surface with a 12.7$\mathrm{mm}$ diameter. The morphology of the porphyrin films and bare glassy carbon were imaged up to 100k-magnification with a Hitachi S-4500 FESEM microscope. In an effort to miniaturize the working electrode, glass-encased carbon fiber microelectrodes were prepared in house as previously described [24,31] and modified with hemin using the same procedure of electropolymerization as outlined for the glassy carbon electrodes. The flow-through experiments were performed in a homemade flow-cell constructed with a transparent plexiglass block in which we machined inner working channels: a first channel of the flow cell housed a carbon fiber microelectrodes working electrode. A second channel was fitted with an $\mathrm{Ag} / \mathrm{AgCl}$ wire as a reference electrode. Downstream, a stainless steel tube inserted in the third channel is used as the auxiliary electrode and also as an outlet for the solution in the flow-through system (Fig. 9a). The flow-cell setup was operated with a Masterflex peristaltic pump and used a Rheodyne 5020 manual injector fitted with a $500-\mu \mathrm{L}$ injection loop. As shown by the arrows in Fig. 9a, the hydrodynamic flow at the electrode surface is lateral and not front-on; the flow embraces the body of the protruding working microelectrode laterally around the $\sim 1-\mathrm{cm}$ cylindrical surface of the exposed fiber. The right choice of the flow rate ensures that the flow is non-turbulent and with no bubble formation. The sensitive surface (protruding tip) is completely immersed in either analyte solution or buffer. The solution first runs laterally on the working microfiber and then exits through the stainless steel cannula, which also acts as the counter electrode.

\section{Results and discussion}

\section{Preparation of hemin-modified glassy carbon (GC) electrode}

Fig. 1a shows a typical cyclic voltammogram of $1.5 \mathrm{mM}$ hemin monomer in dichloromethane with $0.1 \mathrm{M}$ tetrabutylammonium tetrafluoroborate as supporting electrolyte on bare GC electrode at a scan rate of $0.1 \mathrm{~V} \mathrm{~s}^{-1}$. The quasi-reversible reduction of hemin recorded at ca. $-0.4 \mathrm{~V}$ is iron-based and corresponds to the $\mathrm{Fe}{ }^{\mathrm{III}} / \mathrm{Fe}^{\mathrm{II}}$ redox couple. Scanning the potential further negatively gives rise to a second, less reversible, iron-based reduction, $\mathrm{Fe}^{\mathrm{II}} / \mathrm{Fe}^{\mathrm{I}}$, at $c a$. $-1.26 \mathrm{~V}$ vs. $\mathrm{Ag} / \mathrm{AgCl}$. This overall picture is similar to the general behavior of various iron porphyrins, including the dimethyl ester form of hemin in organic solvents $[17,32,33]$. The anodic branch features an irreversible wave at $+1.25 \mathrm{~V} v s$. $\mathrm{Ag} / \mathrm{AgCl}$; this is assigned to the ring-based oxidation producing the porphyrin cation-radical, based on reported assignments in similar systems $[17,34]$. Repetitive scanning over the oxidation wave between $0 \mathrm{~V}$ and $+1.3 \mathrm{~V}$ results in the electrodeposition and growth of a heminbased electroactive film, as evidenced by the gradual increase in the peak currents (Fig. 1b). Similar current growth was reported for the oxidative polymerization of dimethylester-hemin [17]. The growing peak current of consecutive cycles indicates the formation of electroactive film layers on the electrode's surface, capable of mediating further electrolysis of incoming porphyrin monomers at the film-solution interface. As the film thickness increases gradually through the first 10-20 scans, a limit is imposed on further hemin polymerization [17]. The electrodeposited electroactive film is apparent on the GC electrode's surface as a deeply colored thin film, and was stable to rinsing with aqueous or organic solvents.

\section{Surface characterization}

The morphology of the active surface of the electrodeposited hemin-based films was closely examined with FESEM at various
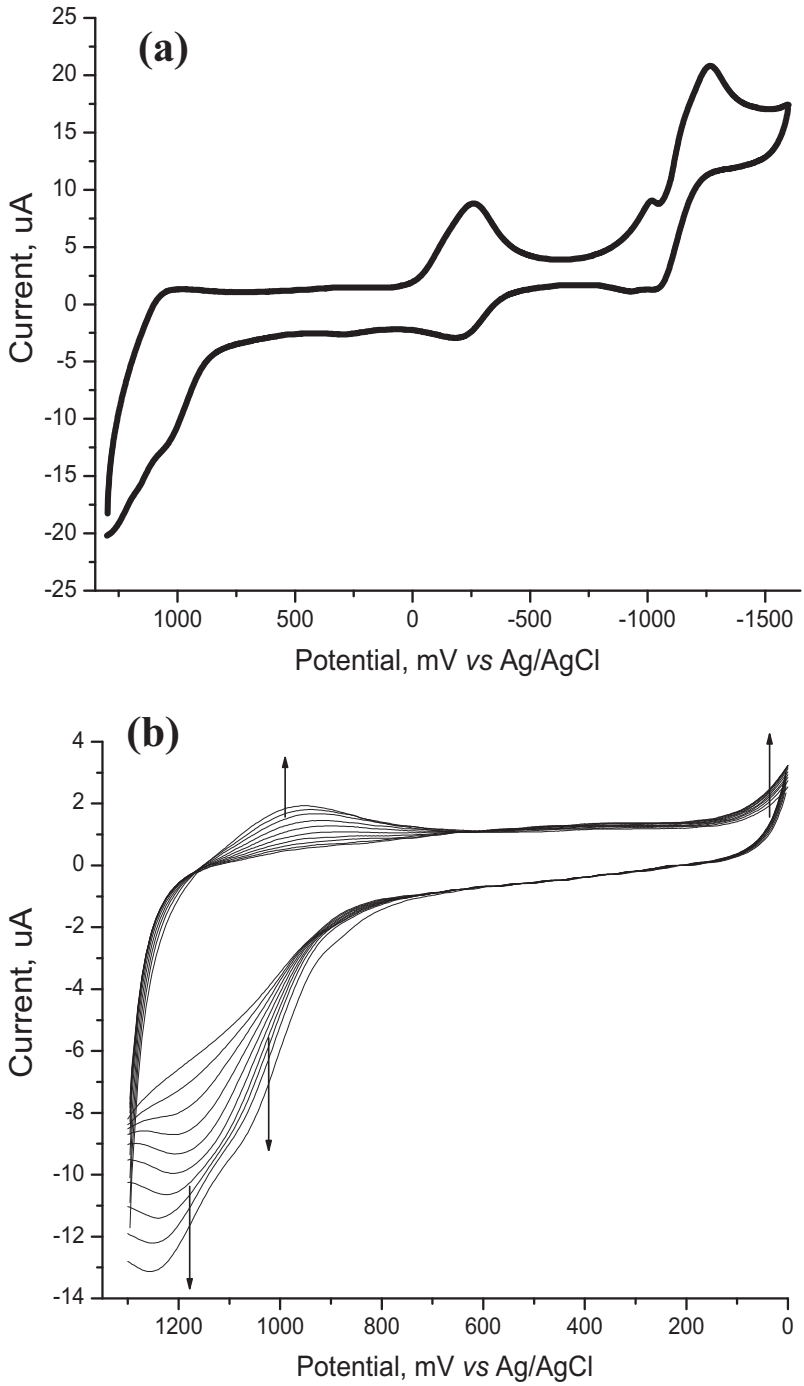

Fig. 1. (a) Cyclic voltammogram (CV) of $1.5 \mathrm{mM}$ solution of hemin monomer in dichloromethane/0.1 $\mathrm{M} \mathrm{TBABF}_{4}$ on a bare GC at $100 \mathrm{mV} \mathrm{s}^{-1}$. (b) Consecutive CV scans within the oxidative branch only in the same solution showing the growth of an electrodeposited film on the electrode's surface.

magnifications and compared, on one hand, with the bare glassy carbon support, and on the other hand, with the iron-free protoporphyrin ring (i.e. ligand with no iron) polymerized under the same conditions (Fig. 2a-f). The bare surface of the glassy carbon was essentially flat; however higher magnifications show few nanoscratches and nano-indentations (Fig. 2b). The observed nanoscale defects seem to serve as starting points for the film growth process; in fact, hemin nano-grains formed within the nano-wells typically act as the seeds from which larger micro-domains are formed [35]. Moreover, an earlier AFM/STM in situ study of electropolymerization revealed that from the first voltammetric cycle the number and size of these islands grow continuously, but at a slower rate because of passivation caused by the first layers, as confirmed by the voltammetric scans [36]. For hemin, these micro-domains tend to coalesce, and then grow higher into shingle-like features of $c a .5 \times 10 \mu \mathrm{m}$ of quasi-uniform orientation (Fig. $2 \mathrm{~d}$ ). Overall, the electro-polymerization of hemin on our glassy carbon electrodes typically results in a relatively uniform coverage. Although the electro-oxidative polymerization processes for hemin and protoporphyrin seem to be similar, the morphologies of the two kinds of films are quite different. In fact, the FESEM images show that protoporphyrin-based films have only a partial coverage on glassy 

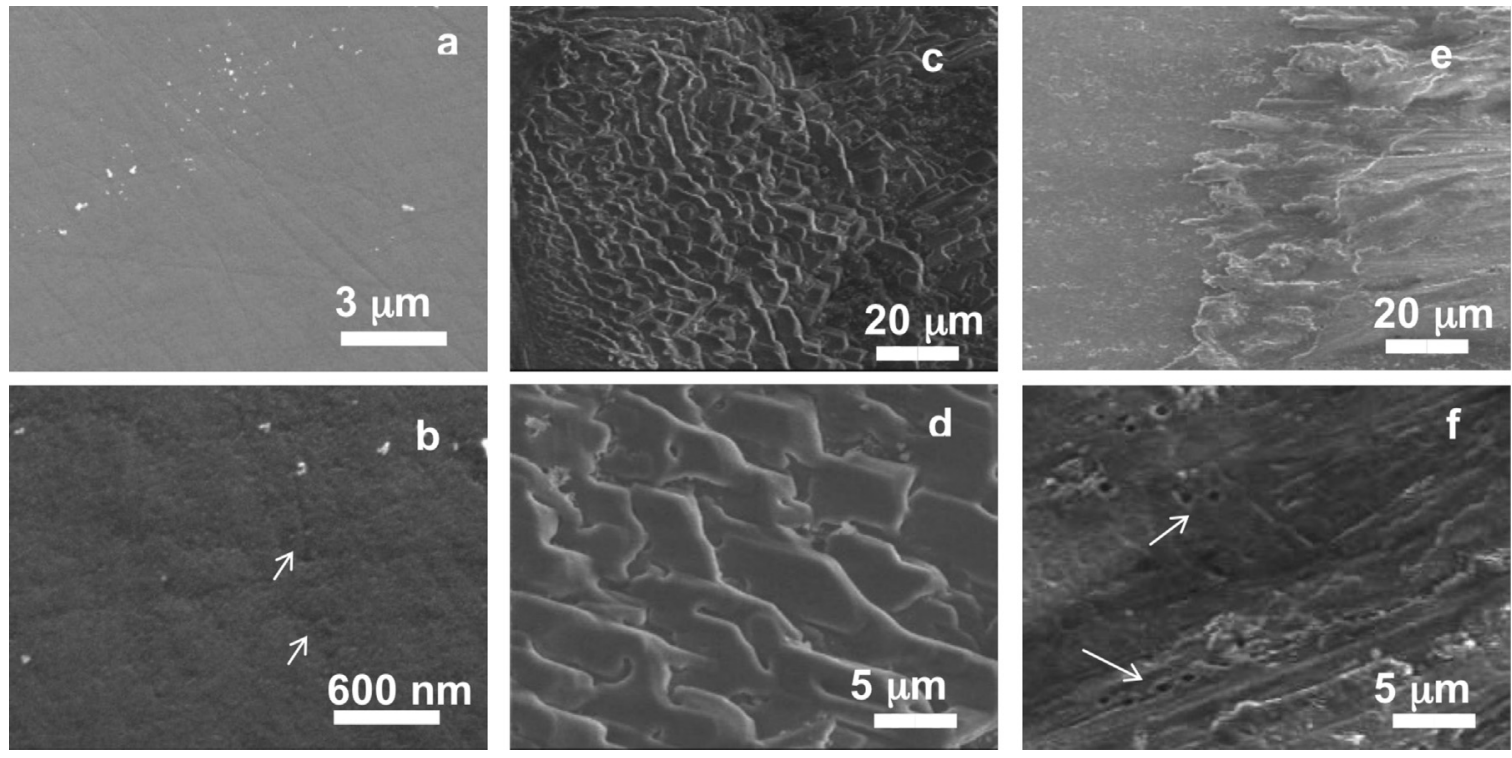

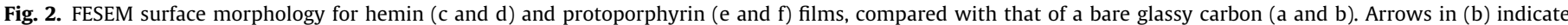
nano-indentations in the bare carbon surface, Arrows in (f) point to several vesicles. See text for details.

carbon electrodes (Fig. 2e). In addition, the overall film growth in the case of protoporphyrin lacked the quasi-uniform orientation observed in hemin-based films, with apparent pockets limiting the spatial growth (Fig. 2f). This may be linked to the stability of the final film, since the protoporphyrin-based films are significantly instable as compared to hemin-based films.

Similar surface characterization was carried out on the bare and hemin-modified carbon fiber electrodes. FESEM analysis shows also in this case a good coverage of the carbon fiber with the polymerized hemin film; however close analysis of the film shows somewhat incomplete patches as well as absence of the shingle-like continuous film structure observed in modified GC discs (Fig. 3).

\section{Response of hemin-modified electrode to peroxynitrite}

\section{Cyclic voltammetry}

Fig. 4 illustrates a typical cyclic voltammetry response of the electro-polymerized hemin film to added aliquots of the peroxynitrite analyte. The modified electrode shows an oxidation peak at about $+1070 \mathrm{mV} v s$. $\mathrm{Ag} / \mathrm{AgCl}$, in the presence of $0.45 \mathrm{mM}$ peroxynitrite in $\mathrm{pH} 10.5$ buffer solution. This peak is not observed for the bare GC electrode (see Figure S1, supplemental information); in fact, in the same conditions, the direct oxidation of peroxynitrite on GC is rather sluggish, with a less-defined peak, and occurs at potentials above $+1350 \mathrm{~V}$ vs. $\mathrm{Ag} / \mathrm{AgCl}$.
The ratio of the peak current of the voltammetric wave of heminmodified electrode in the presence of peroxynitrite to the current measured in absence of this analyte at the same potential, $I / I_{0}$, depends on the scan rate, i.e. the time scale of the experiment. In fact, $I / I_{0}$ gradually decreases as the scan rate is increased for all concentrations studied (Fig. 5). This behavior is typical of an electrocatalytic process [37] where the oxidation of the peroxynitrite substrate is mediated by the hemin polymeric film (Scheme 1).

The peak-shaped catalytic wave is a result of substrate depletion at the film-solution interface during turnover, indicating a fast catalytic oxidation of peroxynitrite and diffusion-controlled replenishment from the bulk. The catalytic process as described above is not observed with protoporphyrin-only based films (Fig. 4). This fact points to a crucial role played by the bound iron atom in hemin-based films, which shows that the iron center is necessary for enabling the observed oxidative catalytic turnover of peroxynitrite oxidation. This is consistent with literature reports on the chemical interaction of peroxynitrite with metalloporphyrins, including iron and manganese porphyrins [12,13,38,39]. The reported interactions are essentially enabled by the porphyrinbound metallic center. Radi et al. and Groves et al. reported fast reactions of manganese-based porphyrins with peroxynitrite, and implicitly invoked a mechanism driven by direct interaction of peroxynitrite with the metallic center $[12,38,40]$. Similarly, Groves et al. reported that the chemical interaction and decomposition of peroxynitrite with a set of iron porphyrins in solution is based
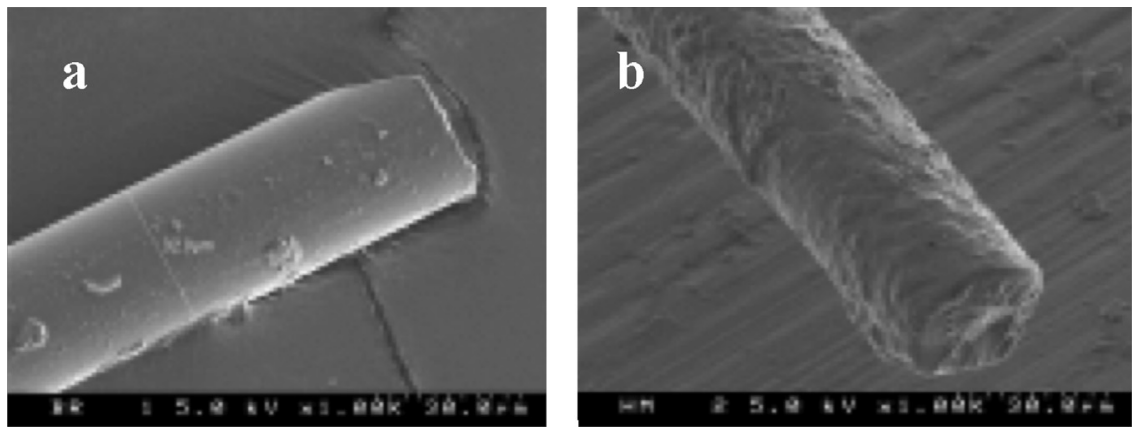

Fig. 3. Typical surface morphology of (a) bare and (b) hemin-modified $30-\mu \mathrm{m}$ carbon fiber as analyzed by FESEM. 


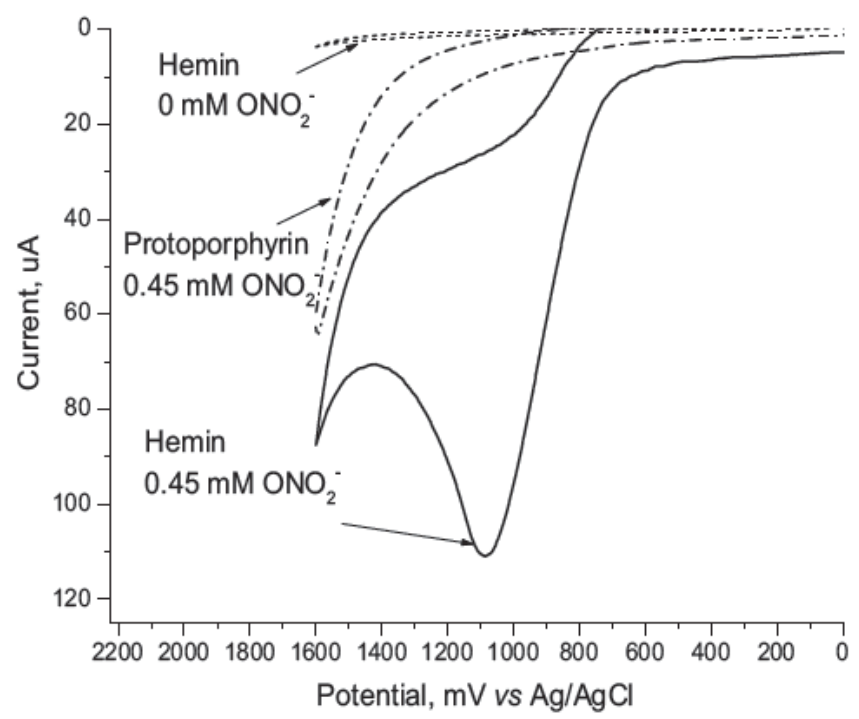

Fig. 4. Cyclic voltammograms at $150 \mathrm{mV} \mathrm{s}^{-1}$ in $\mathrm{pH} 10.5$ CAPS buffer solution for: hemin with no peroxynitrite $\left(\mathrm{ONO}_{2}{ }^{-}\right)$, and for protoporphyrin and hemin in the presence of $0.45 \mathrm{mM} \mathrm{ONO}_{2}^{-}$.

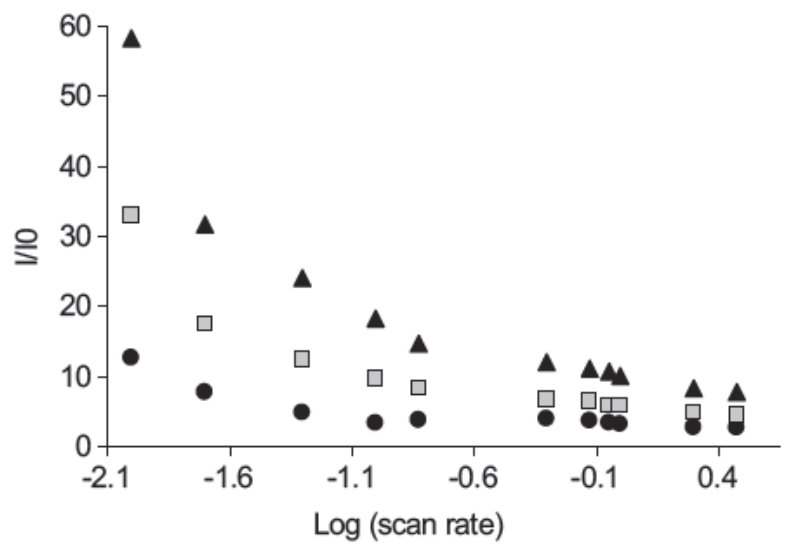

Fig. 5. Dependence of the catalytic efficiency $I / I_{0}$ (see text) on the scan rate for hemin-modified GC in pH 10.5 buffer at $(\bullet) 0.55 \mathrm{mM}$, ( $\square) 0.90 \mathrm{mM}$, and $(\Delta) 1.45 \mathrm{mM}$ peroxynitrite concentration.

at the $\mathrm{Fe}^{\mathrm{III}}$ center, and yields to the isomerization product, nitrate, through a sequence of binding, "in-cage" dissociation, and rebound, utilizing an $\mathrm{Fe}^{\mathrm{IV}}=\mathrm{O}$ intermediate [39].

In our case, while the oxidation of the hemin film is reported as porphyrin-based $[17,34]$ the presence of the iron metal is vital, and locally mediates the inner electron transfer from the peroxynitrite

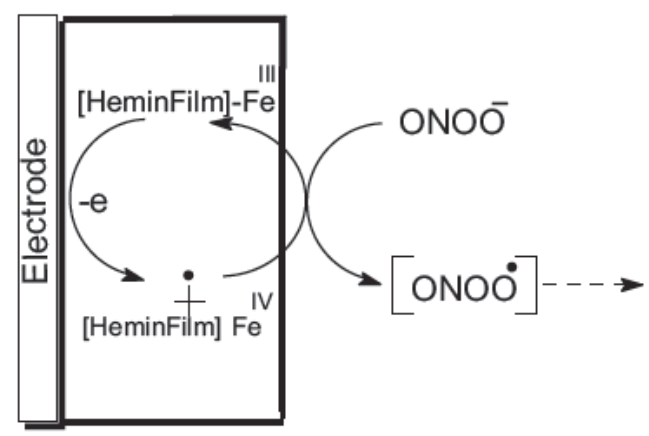

Scheme 1. Electrocatalytic oxidation scheme of peroxynitrite by hemin-modified GC electrode.

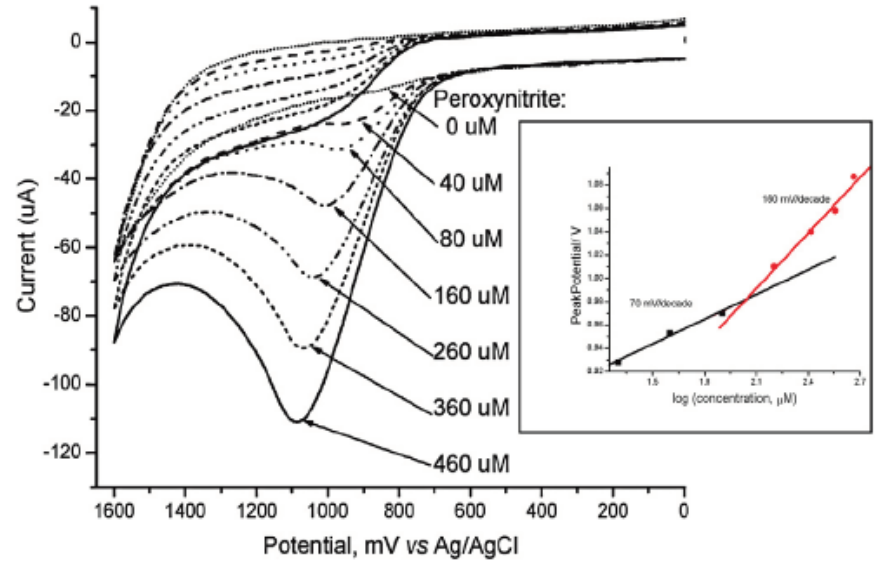

Fig. 6. Typical response of hemin-modified GC in pH 10.5 CAPS buffer to different peroxynitrite concentrations from 40 to $460 \mu \mathrm{M}$ at a scan rate of $150 \mathrm{mV} \mathrm{s}^{-1}$. Inset: peak potential of catalytic current as a function of peroxynitrite's concentration.

substrate to the oxidizing porphyrin ring, acting as an "antenna" for oxidizing equivalents from the electrode.

The catalytic oxidation current on our hemin-modified electrodes increases with increasing peroxynitrite concentration (Fig. 6). Also, increasing the peroxynitrite concentration causes the peak potential of the catalytic peak to shift toward positive values. Close analysis of the potential change as function of the concentration reveals two concentration regimes where the slope increases from $70 \mathrm{mV}_{\text {decade }}^{-1}$ to a limiting slope of $c a .160 \mathrm{mV}^{\text {decade }}{ }^{-1}$ (inset Fig. 6).

Although the behavior described was typically reversible, there was a small variability in the slopes before and after high concentration range. However, it is important to note that this cyclic voltammetry behavior does not affect the sensitivity of the steadystate response of the electrode, which, in amperometry, operates at a set potential, e.g. $+0.7 \mathrm{~V}$ vs. $\mathrm{Ag} / \mathrm{AgCl}$ (vide infra Section 3.3.2). While the origin of these two limiting slopes is not obvious at this point, this general behavior indicates that the observed catalytic process is associated with a step of metal-substrate binding interaction and not simple outer-sphere electron transfer mediation.

$\mathrm{Fe}^{\mathrm{III}}$-hemin-mediated peroxynitrite decomposition reactions, on their own, can yield various levels of nitrite and nitrate $[40,42]$. Given this possible route, one may think of an alternative mechanism, whereby our observed catalytic decomposition is not driven electrochemically, but rather chemically by the porphyrin units at the film-solution interface, followed by electrocatalytic oxidation of nitrite or some other effect of nitrate. To rule out this possibility, we performed a series of control experiments that examine the effect of nitrite or nitrate on the voltammetric waves observed. We have recorded the response of hemin-modified electrodes to millimolar levels of nitrite and nitrate and contrasted it with the typical response observed with a much lower $(400 \mu \mathrm{M})$ concentration of peroxynitrite (Figure S2, Supporting Information). The peak current observed with the $400 \mu \mathrm{M}$ concentration of peroxynitrite is over 7 times that observed with $1 \mathrm{mM}$ nitrite while the response with $1 \mathrm{mM}$ nitrate is relatively mute. This rules out the possibility that peroxynitrite is simply converted to nitrite on hemin in the film, and confirms that the electrocatalytic process observed is not due to nitrite (or nitrate). Another support for this conclusion comes from spectroscopic monitoring of peroxynitrite spontaneous decay in buffer solution in the presence and absence of a large GC electrode modified with hemin film. Peroxynitrite is known to spontaneously decompose in solution with a rate that depends on $\mathrm{pH}$ [24]. If the hemin film further participates in this decay, one would witness an 


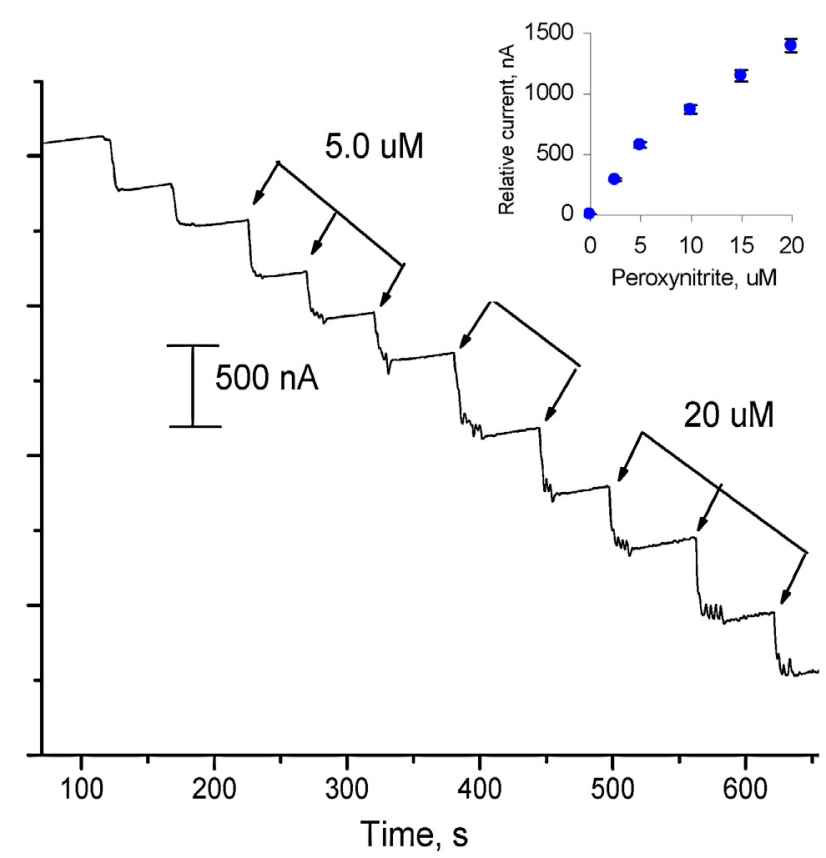

Fig. 7. Typical amperometric response curve obtained using a hemin modified electrode polarized at $+0.7 \mathrm{~V} v s$. $\mathrm{Ag} / \mathrm{AgCl}$. The inset illustrates the resulting calibration curve.

enhancement in the decomposition rate in the presence of heminmodified electrodes. Figure S3 in supporting information shows that the rate of peroxynitrite decay in CAPS buffer in the presence and absence hemin-modified electrodes is essentially the same. Both spectroscopic and voltammetric control experiments above confirm that the electrochemical response in the presence of peroxynitrite is the result of a direct electrocatalytic process mediated by hemin on the modified electrodes.

As shown in Fig. 6, the catalytic current increases as the concentration of peoxynitrite increases. The catalytic efficiency is expressed as the ratio $\left(I / I_{0}\right)$, i.e. the catalytic peak current $(I)$ in the presence of peroxynitrite, normalized to the current in its absence $\left(I_{0}\right)$. The plot of catalytic efficiency as a function of substrate's concentration is reported in supporting information (Figure S3). $I / I_{0}$ increases as a function of peroxynitrite's concentration. However, at large concentrations, this efficiency tends to curve down and shows the typical behavior of enzyme saturation kinetics. In this context, both non-linear fitting using Michaelis-Menten type of kinetics (Fig. 7) and Lineweaver-Burk double reciprocal analysis of the data, Inset Figure S4, yield a Michaelis-Menten constant, $K_{\mathrm{M}}$ of ca. $0.7 \mathrm{mM}$. Similar $K_{\mathrm{M}}$ constants in the 0.37-0.62 mM range were reported for the decomposition of peroxynitrite by micromolar amounts of water-soluble Fe(III) porphyrin complexes [13]. Although the mechanism of the reported process is distinct from our case, in which the catalysis is driven by electrochemical oxidation of the polymerized Fe-porphyrin film, the similar values of $K_{\mathrm{M}}$ indicate the control of our catalytic process by an initial binding interaction of the substrate to Fe-porphyrin centers in the film, similar to the interactions reported for solution-based decomposition [13].

We studied the catalytic oxidation of peroxynitrite on heminmodified electrodes as a function of $\mathrm{pH}$. The $\mathrm{pH}$ range was limited to $\mathrm{pH}$ above 8.5 due to shorter lifetime of peroxynitrite, at low pHs [12]. The potential of the catalytic oxidation peak increases as the $\mathrm{pH}$ is increased, as expected for a proton-dependent process. The $\mathrm{pH}$ dependence study results are reported in supporting information (Figure S5).

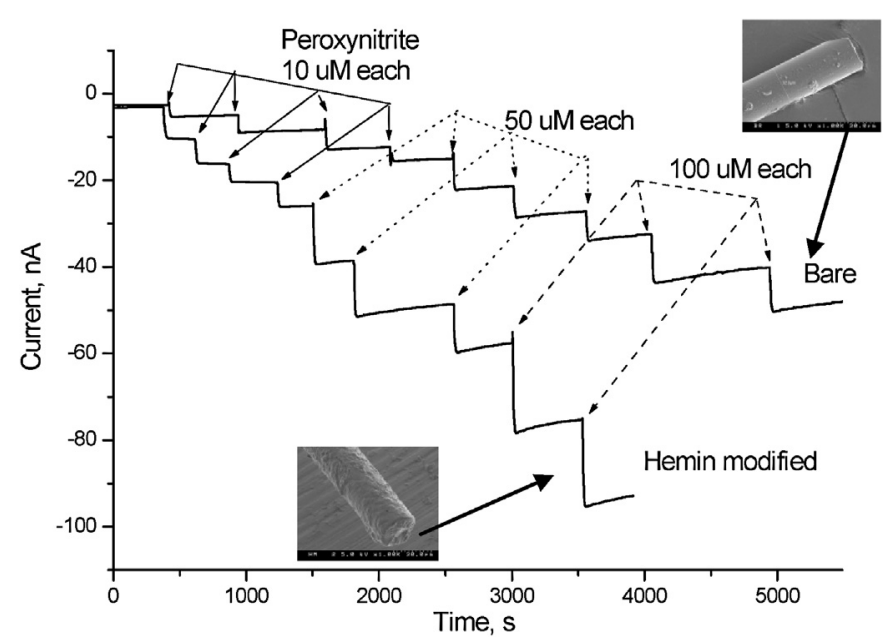

Fig. 8. Typical staircase amperometric response curves for bare and hemin-modified $30 \mu \mathrm{m}$ diameter carbon fiber polarized at $+0.7 \mathrm{~V} v \mathrm{~s}$. Ag/AgCl.

\subsubsection{Amperometry}

We next performed several time-based amperometry tests to further evaluate the intrinsic electrochemical response of the hemin-modified electrodes to peroxynitrite and potential use as PON sensors. The current was measured in response to added amounts of peroxynitrite from standard solutions in $10.5 \mathrm{pH}$ buffer solution. A typical amperometric dose-response curve is shown in Fig. 7. Each arrow indicates the amount and addition time of $\mathrm{ONO}_{2}{ }^{-}$aliquots to stirred $\mathrm{pH} 10.5$ buffer solution. Typically, the concentration response of the modified electrodes under increasing PON concentration (staircase response) reverts back to background currents when PON solution is replaced with buffer at the same set potential and increases again with PON additions reproducing the original staircase response and sensitivity.

The peroxynitrite sensor that we are targeting are to be used, among other targets, in the monitoring of uncoupling pathways leading to peroxynitrite as a side product during turnover of nitric oxide synthase $[41,43]$. Under these conditions both nitric oxide and peroxynitrite can be generated. We therefore tested the performance of these electrodes in the presence of nitric oxide. The response of the hemin-modified electrode was tested with a series of nitric oxide aliquots, and subsequently with a series of similar concentrations of peroxynitrite analyte to test the relative response. Results are reported in supporting information (Figure S6), and show that the response of the hemin-electrodes to peroxynitrite is significantly larger than the response to nitric oxide, particularly at low concentrations.

\section{Miniaturization and flow injection amperometry}

There are some advantages expected from miniaturization, such as faster response times, better spatial-temporal resolution and less invasive measurements [42]. Thus, in an effort to miniaturize the working electrode, we prepared glass-encased carbon fiber microelectrodes in-house and modified them with polymerized hemin films using the same procedure described above for disc electrodes. We tested the response of hemin-modified carbon fiber electrodes in the presence of peroxynitrite using amperometry both in a stirred solution in the regular three-electrode cell and in a homemade flow cell. Typical amperometric response curves in a stirred 3-electrode cell for both bare and hemin-modified carbon fibers are shown in Fig. 8. These results show that the intrinsic sensitivity of the hemin-modified carbon fiber to peroxynitrite is ca. $2 \times$ times higher than that of a bare fiber. This result shows that the intrinsic response of the hemin film alone as a platform for peroxynitrite detection on carbon fibers is rather at the low end. 
A
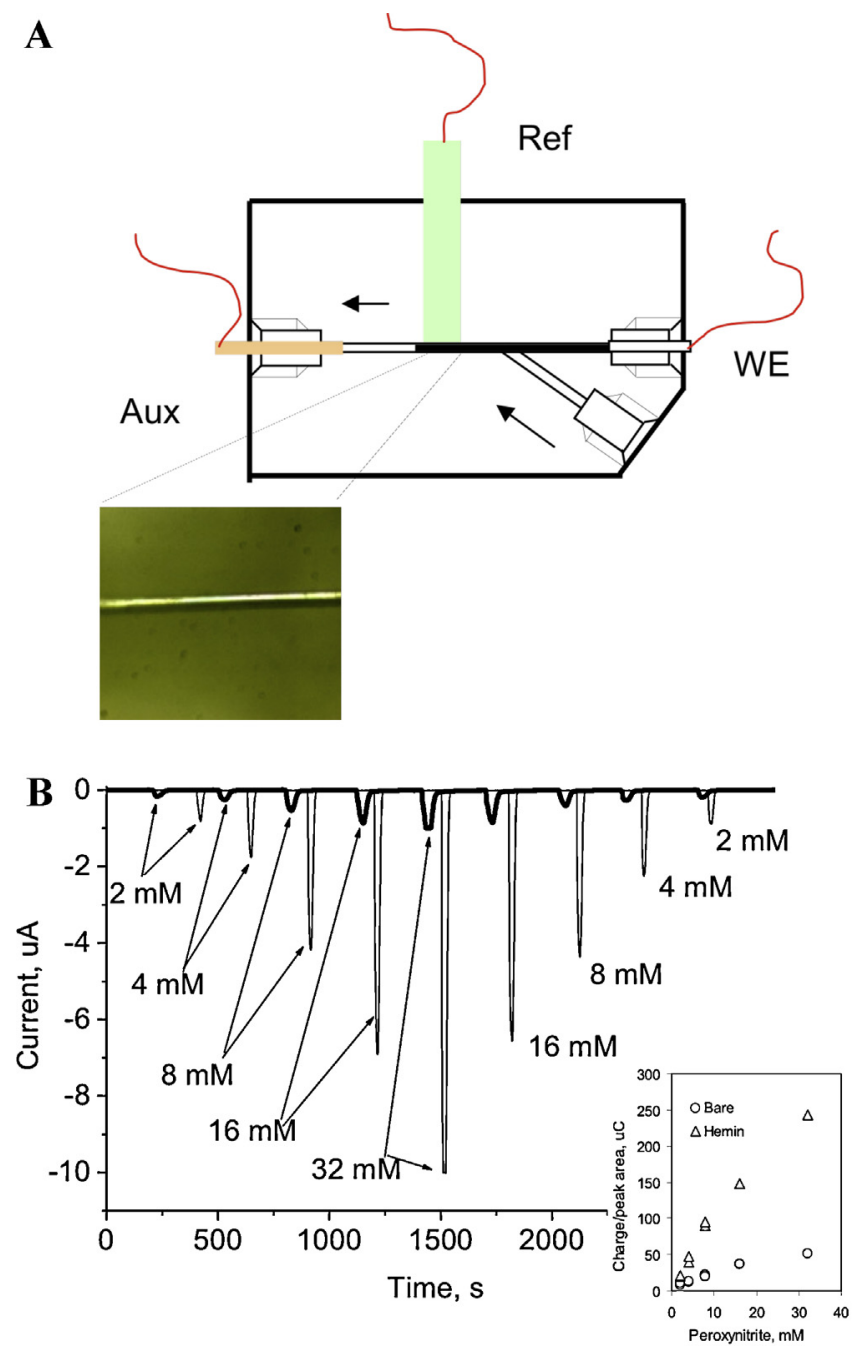

Fig. 9. (a) Geometry of the homemade flow-cell and setup used in the flow analysis of peroxynitrite using bare and modified carbon fiber microelectrodes; WE denotes the position of the working microfiber electrode, Ref and Aux are the positions of the reference and counter electrodes respectively (see Section 2 for details). (b) Peroxynitrite peaks recorded for bare $(-)$ and hemin-modified $(-) 30-\mu \mathrm{m}$ carbon fiber; inset: plot of peak areas as a function of peroxynitrite concentration for both bare $(\bigcirc)$ and modified fibers $(\triangle)$.

This is to be compared with our prior report on the more complex platform PEDOT/hemin matrix prepared using the layer-by-layer electrodeposition of PEDOT and hemin polymers, and which yields a response of over $50 \times$ times that seen with hemin alone [24]. Also, the lower response observed for hemin microelectrodes correlate with our FESEM analysis and derived observations pointing to an overall lower quality and coverage of the hemin film on the carbon microfiber compared to PEDOT/hemin microelectrodes [24]. We also tested the response of our modified carbon fiber electrodes in a flow cell setting (Fig. 9a). One of the advantages of using a flowcell is the convective transport of analyte, which yields to reduction in the noise and fast response times. A brief sketch of the homemade flow cell and electrode setting used in our measurements is shown in Fig. 9b. Although performed rather at a high concentration range, our initial measurements using bare and modified carbon fibers in our flow-through setup show, as expected, higher response of the polymerized hemin film-modified electrode over bare carbon electrodes for the catalytic oxidation of peroxynitrite. Using the relative peak areas at various $\mathrm{ONO}_{2}{ }^{-}$concentrations, we show that the response of the simple hemin carbon fiber electrodes is at least 4 times larger than the bare carbon microelectrode at this concentration range (Fig. 9b). The inset in Fig. 9b shows the resulting plot of various peak areas (charge) as a function of peroxynitrite concentration.

\section{Conclusion}

In this paper we have reported the intrinsic response of hemin films to peroxynitrite. This simple platform was used both on carbon disc and fiber electrodes. Results show that hemin electropolymerized films mediate a direct electrocatalytic oxidation of peroxynitrite and that the catalytic response observed is not the result of hemin-mediated decomposition byproducts such nitrite. Hemin electrodes preparation is simple and exhibits moderate response compared with the more complex nanostructured hemin/PEDOT films. Hemin-modified electrodes and their observed electrocatalytic oxidation can be used as simple amperometric sensors for peroxynitrite detection even in the presence of nitric oxide as an interfering analyte. Additional work is currently underway for improving the detection limit and selectivity using other metalloporphyrins as electrocatalysts for peroxynitrite sensing.

\section{Acknowledgements}

This research is funded in part by The National Science Foundation (to MB, Grant CHE-0848820), by an FRD grant from Ohio Board of Regents, and by funds from Cleveland State University, and by the National Scientific Research Agency (to SFP, Project PNII 184-2011, UEFISCDI-ANCS).

\section{Appendix A. Supplementary data}

Supplementary data associated with this article can be found, in the online version, at http://dx.doi.org/10.1016/j.aca.2013.03.057.

\section{References}

[1] W.A. Pryor, G.L. Squadrito, Am. J. Physiol. Lung Cell. Mol. Physiol. 268 (1995) L699-L722.

[2] J.S. Beckman, Chem. Res. Toxicol. 9 (1996) 836-844.

[3] T.C. Douki, J. Cadet, B.N. Ames, Chem. Res. Toxicol. 9 (1996) 3-7.

[4] A. Daiber, M. Mehl, V. Ullrich, Nitric oxide: Biol. Chem. 2 (1998) 259-269.

[5] R.S. Sodum, E.S. Fiala, Chem. Res. Toxicol. 14 (2001) 438-450.

[6] Editorial, Chem. Res. Toxicol. 11 (1998) 1.

[7] T. Akaike, Y. Noguchi, S. Ijiri, K. Setoguchi, M. Suga, Y.M. Zheng, B. Dietzhold, H. Maeda, Proc. Natl. Acad. Sci. U.S.A. 93 (1996) 2448-2453.

[8] J.R. Lancaster, Proc. Natl. Acad. Sci. U.S.A. 91 (1994) 8137-8141.

[9] H. Ischiropoulos, J.S. Beckman, J.P. Crow, Y.Z. Ye, J.A. Royall, N.W. Kooy, Methods Enzymol. 7 (1995) 367-373.

[10] G. Ferrer-Sueta, L. Ruiz-Ramirez, R. Radi, Chem. Res. Toxicol. 11 (1998) 720-721.

[11] S.F. Peteu, S. Banihani, M.M. Gunesekera, P. Peiris, O.A. Sicuia, M. Bayachou, in: M. Hepel, S. Andreescu (Eds.), Oxidative Stress and Antioxidants: Diagnosis and Therapy, ACS Symposium Series 1083, Stanford University Press, Washington, DC, 2012, pp. 311-339.

[12] G. Ferrer-Sueta, I.S. Batinic-Haberle, I. Spasojevic, I. Fridovich, R. Radi, Chem. Res. Toxicol. 12 (1999) 442-449.

[13] M.P. Jensen, D.P. Riley, Inorg. Chem. 41 (2002) 4788-4797.

[14] J.H. Lee, J.A. Hunt, J.T. Groves, J. Am. Chem. Soc. (1998) 7493-7501.

[15] J.P. Crow, Arch. Biochem. Biophys. 371 (1999) 41-52.

[16] K.A. Macor, T.G. Spiro, J. Am. Chem. Soc. 105 (1983) 5601-5607.

[17] J.N. Younathan, K.S. Wood, T.J. Meyer, Inorg. Chem. 31 (1992) 3280-3285.

[18] N. Nakashima, T. Tokunaga, H. Owaki, H. Murakami, T. Sagara, Colloids Surf. A: Physicochem. Eng. Aspects 169 (2000) 163-170.

[19] C.G. Nan, Z.Z. Feng, W.X. Li, D.J. Ping, C.H. Qin, Anal. Chim. Acta 452 (2002) $245-254$.

[20] J. Chen, U. Wollenberger, F. Lisdat, B.X. Ge, F.W. Scheller, Sens. Actuators B: Chem. (2000) 115-120.

[21] M. Trujillo, M. Naviliat, M.N. Alvarez, G. Peluffo, R. Radi, Analusis 28 (2000) 518-527.

[22] C. Amatore, S. Arbault, D. Bruce, P. de Oliveira, M. Erard, M. Vuillaume, Chem. Eur. J. 7 (2001) 4171-4179.

[23] J. Xue, J.S. Chen, Y.H. Xian, L.T. Jin, Anal. Chem. 72 (2000) 5313-5321.

[24] S. Peteu, P. Peiris, E. Gebremichael, M. Bayachou, Biosens. Bioelectron. 25 (8) (2010) 1914-1921. 
[25] W.A. Pryor, X. Jin, W.H. Koppenol, M. Ngu-Schwemlein, G.L. Squadrito, P.L. Uppu, R.M. Uppu, Free Radic. Biol. Med. 18 (1995) 75-83.

[26] M.N. Hughes, H.G. Nicklin, J. Chem. Soc. A: Inorg. Phys. Theor. (1971) 164-168.

[27] J.W. Reed, H.H. Ho, W.L. Jolly, J. Am. Chem. Soc. 96 (1974) 1248-1249.

[28] R.C. Plumb, J.O. Edwards, J. Phys. Chem. 96 (1992) 3245-3247.

[29] R.M. Uppu, W.A. Pryor, Anal. Biochem. 236 (1996) 242-249.

[30] D.S. Bohle, P.A. Glassbrenner, B. Hansert, Methods Enzymol. 269 (1996) 302-311.

[31] K.T. Kawagoe, J.B. Zimmerman, R.M. Wightman, J. Neurosci. Methods (1993) 225-240.

[32] K.M. Kadish, D.G. Davis, Ann. N. Y. Acad. Sci. 206 (1973) 495-503.

[33] K.M. Kadish, G. Larson, Bioinorg. Chem. 7 (1977) 95-105.

[34] D.R. English, D.N. Hendrickson, K.S. Suslick, Inorg. Chem. 22 (1983) 367-368.
[35] A.V. Udal'tsov, M. Tosaka, G. Kaupp, J. Mol. Sci. 660 (2003) 15-23.

[36] B. Duong, R. Arechabaleta, N.J. Tao, J. Electroanal. Chem. 447 (1998) 63-69.

[37] A.J. Bard, L.R. Faulkner, Elelctrochemical Methods: Fundamentals and Applications, Second ed., Wiley, New York, 2001.

[38] J. Lee, J.A. Hunt, J.T.J. Groves, Am. Chem. Soc. 120 (1998) 6053-6061.

[39] J. Lee, J.A. Hunt, J.T.J. Groves, Am. Chem. Soc. (1998) 7493-7501.

[40] G. Ferrer-Sueta, D. Vitturi, I. Batinic-Haberle, I. Fridovich, S. Goldstein, G. Czapski, R. Radi, J. Biol. Chem. 278 (2003) 27432-27438.

[41] M. Bayachou, J.A. Boutros, J. Am. Chem. Soc. 126 (2004) 12722-12723.

[42] S.F. Peteu, M.T. Widman, R.M. Worden, Biosens. Bioelectron. 13 (1998) 1197-1203.

[43] R.H. Perera, P.M. Peiris, S.F. Peteu, M. Bayachou, Electroanalysis 24 (2012) 37-41. 